\title{
3D POINT CLOUD IN THE EVALUATION OF PROCESSES THAT GENERATE INSTABILITY OF THE LUMBAR SPINE
}

\author{
NUVEM DE PONTOS TRIDIMENSIONAL NA AVALIAÇÃO DE PROCESSOS QUE GERAM \\ INSTABILIDADE DA COLUNA LOMBAR
}

\section{NUBE DE PUNTOS TRIDIMENSIONAL EN LA EVALUACIÓN DE PROCESOS QUE GENERAN INESTABILIDAD DE LA COLUMNA LUMBAR}

José Luis González Gallegos ${ }^{1}$, Tania del Socorro Vergara Gómez², Armando García Hernández², Ana Karen lbarra Martínez², Alejandro García González², Rita Quetziquel Fuentes Aguilar², José María Jiménez Ávilla

\begin{abstract}
Objective: To integrate patients with lumbar instability in a multisensor platform in the process of assessment and diagnosis, assigning quantitative parameters for the sagittal balance (SB) and muscle function. Methods: Experimental study involving adult patients diagnosed with diseases that cause alterations in the SB, that were or were not submitted to surgery with posterior instrumentation and fusion. Each patient underwent anthropometric measurements in body composition scale; a kinesiological analysis using a multisensor platform consisting of depth camera to static/dynamic analysis for the quantitative measurement of SB, and surface electromyography to capture the level of abdominal and lumbar muscles activation and through flexion and extension. Results: Seven adult patients: five females (62.5\%)and two men (37.5\%) with a mean age 48 years. Images with depth cameras resulted in a SB of from -6.4 to $+5.3 \mathrm{~cm}$ (average $-5.7 \mathrm{~cm}$ ). In individuals with positive sagittal balance the percentage of activation (PA) of the abdominal muscles was 58.5\% and the lower back lumbar was 75.25\%; patients with negative SB integrated the PA of the abdominal muscles of $70.25 \%$ and lumbar of $65 \%$; the patient with neutral SB exhibited activation of the abdominal muscles of $87.75 \%$ and lumbar muscles of 78.25\%. Conclusions: We observed a trend towards positive SB in patients with overweight and obesity by BMI, as well as increased activation of the abdominal muscles. The multi sensor platform is a useful tool for the diagnosis and prognosis of diseases involving sagittal imbalance.
\end{abstract}

Keywords: Joint instability; Lumbosacral region; Postural balance; Electromyography.

\section{RESUMO}

Objetivo: Integrar os pacientes com instabilidade lombar em uma plataforma multissensor no processo de avaliação e diagnóstico, atribuindo parâmetros quantitativos para o equilíbrio sagital (ES) e função muscular. Métodos: Estudo experimental com pacientes adultos diagnosticados com doenças que causam alterações no ES, submetidos ou não à cirurgia com instrumentação e fusão por via posterior. Em cada paciente realizaram-se medidas antropométricas em balança de composição corporal, análise cinesiológica utilizando uma plataforma multissensor constituída por câmera profundidade para análise estática/dinâmica para medição quantitativa do ES e eletromiografia de superfície para capturar o nível de ativação da musculatura abdominal e lombar por meio de flexão e extensão. Resultados: Sete pacientes adultos: cinco mulheres (62,5\%) e dois homens (37,5\%) com média de idade de 48 anos. As imagens com câmeras de profundidade resultaram em ES de $-6,4+5,3 \mathrm{~cm}$ (média -5,7cm). Nos indivíduos com equilíbrio sagital positivo, o percentual de ativação (PA) dos músculos abdominais foi 58,5\% e dos músculos lombares foi 75,25\%; nos pacientes com ES negativo integrado, a PA dos músculos abdominais foi de 70,25\% e lombar 65\%; o paciente com ES neutro apresentou ativação dos músculos abdominais de 87,75\% e dos músculos lombares, de 78,25\%. Conclusão: Observamos uma tendência ao ES positivo em pacientes com sobrepeso e obesidade pelo IMC, bem como ao aumento da ativação dos músculos abdominais. A plataforma multissensor constitui uma ferramenta útil para o diagnóstico e prognóstico de doenças com desequilíbrio sagital.

Descritores: Instabilidade lombar; Região lombossacral; Equilíbrio postural; Eletromiografia.

\section{RESUMEN}

Objetivo: Integrar a pacientes con inestabilidad lumbar a una plataforma multisensor en su proceso de evaluación y diagnóstico, dando parámetros cuantitativos para el balance sagital (BS) y la función muscular. Métodos: Estudio de tipo experimental con pacientes adultos diagnosticados con patologías que causan alteraciones en el BS, unos no operados, y otros operados con instrumentación y fusión posteriores. Cada paciente fue sometido a mediciones antropométricas en báscula de composición corporal; un análisis kinesiólogo utilizando una plataforma multisensor constituida por cámara de profundidad para el análisis estático/dinámico para la medición cuantitativa del BS, y un electromiógrafo de superficie captó el grado de activación muscular en región abdominal y lumbar, mediante movimientos de flexión y extensión. Resultados: Siete pacientes adultos: cinco mujeres (62.5\%), dos hombres (37.5\%); media de edad de 48 años. Las imágenes con cámaras de profundidad resultaron en un BS de $-6.4 \mathrm{a}+5.3 \mathrm{~cm}$ (promedio- $5.7 \mathrm{~cm}$ ). Aquellos con BS positivo el porcentaje de activación (PA) de los músculos abdominales fue de $58.5 \%$ y la de los lumbares fue de 75.25\%; pacientes con BS negativo integraron un PA de los músculos abdominales de 70.25\% y de lumbares de 65\%; el paciente con balance sagital neutro tuvo activación de la musculatura abdominal de $87.75 \%$ y lumbar de $78.25 \%$. Conclusiones: Observamos tendencia al BS positivo en pacientes con sobrepeso y obesidad por IMC, así como mayor activación de músculos abdominales. La plataforma multisensor constituida es una herramienta útil para el diagnóstico y pronóstico de enfermedades con desbalance sagital.

Descriptores: Inestabilidad de la articulación; Región lumbosacra; Balance postural; Electromiografía.

1. Instituto Mexicano del Seguro Social, Centro Médico Nacional de Occidente, Unidad Médica de Alta Especialidad. Servicio de Ortopedia y Traumatología. Guadalajara, Jalisco, Mexico. 2. Instituto Tecnológico de Monterrey, División de Biotecnología y Salud, Departamento de Ingeniería Biomédica. Guadalajara, Jalisco, Mexico.

Study conducted at the Instituto Tecnológico de Monterrey, Campus Guadalajara. División de Biotecnología y Salud, Departamento de Ingeniería Biomédica, Mexico.

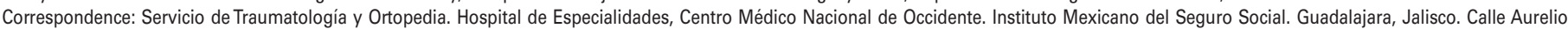
González, 2298. Colonia Jardines Alcalde, México, C.P. 44298. jose.luis.glez.gall@gmail.com 


\section{INTRODUCTION}

Spinal stability is the capacity of the spine, under physiological loads, to limit displacement patterns so as not to damage or irritate the spinal cord and nerve roots, and to prevent incapacitating deformities or pain caused by structural changes. ${ }^{1,2}$ A physiologically stable spine is maintained in proper sagittal balance, where the individual is able to stay in an upright position with minimal muscular effort, ensuring that the center of gravity of the body is kept in harmony within a support base. Sagittal balance is the result of the interaction between the pelvic and spinal bone morphologies, the mechanical behavior of the discs and ligaments, muscle strength and resistance, and the capacity to introduce compensatory mechanisms related to the balance of the trunk and the position of the lower limbs. ${ }^{3}$

As the principal cause of degenerative mechanisms, the spine may become unstable, leading to a loss of the spinal capacity to maintain normal displacement patterns without any initial neurological deficit, significant deformity, or disabling pain. ${ }^{4}$ As a result of degeneration and instability, there is a gradual loss of sagittal balance that begins with a decrease in the height of the intervertebral disc and a cascade of compensatory mechanisms in which changes occur in the position of the hips, pelvis and knees, in order to restore sagittal balance to a neutral position, ${ }^{5-7}$ enabling a plumb line from C7 to remain, clinically, between both malleoli. ${ }^{8}$ But this situation is not profitable because, as measured electromyographically, more muscular energy is required to maintain this position, causing low back pain ${ }^{9}$ and inevitably leading to imbalance in the sagittal plane.

There is growing evidence that the deep abdominal muscles and the lumbar multifidus are especially adversely affected by the presence of acute or chronic low back pain and lumbar instability. The occurrence of compensatory substitution by global muscular systems in the presence of local muscular system dysfunction has also been reported. ${ }^{10}$

With advances in technology, instruments for the three-dimensional reconstruction of the human body have been developed with the goal of explaining the complexity of its biomechanics, and have been used in clinical practice as diagnostic tools for degenerative and congenital diseases. In the search for answers, interest in the study of the healthy spine, its related pathologies, and the evaluation of posture has increased, and has already provided an important solution for integrating functional information in a quantitative way.

Depth detection cameras have gained ground in various applications using an infrared depth sensor and a color camera to capture real time 3D images to measure the functional capacities of the skeleton. They have already been clinically tested for the assessment of postural control, ${ }^{11}$ the evaluation of risks of falling at home in both children $^{12}$ and the elderly, quantification of upper limb function, ${ }^{13}$ physical rehabilitation, ${ }^{14}$ sports, ${ }^{15}$ and exercise, ${ }^{16}$ among others.

The objective of this study is to integrate point cloud reconstruction using depth cameras, with the measurement of muscle response using electromyography and anthropometric data in a Multisensor Platform, in order to evaluate patients diagnosed with degenerative processes that cause instability of the lumbar spine, whether operated on or not, as part of their clinical and functional assessment, yielding quantitative parameters on sagittal balance and muscle function.

\section{MATERIALS AND METHODS}

An experimental study was conducted. The study universe included patients from the spine clinic of the Orthopedics Service of the Unidad Médica de Alta Especialidad Centro Médico de Occidente del Instituto Mexicano del Seguro Social [Medical Unit of the Western Specialty Medical Center of the Mexican Social Security Institute] in Guadalajara, Mexico. The subjects had to have an established diagnosis of pathologies of the lumbar and thoracolumbar spine that could potentially cause changes in sagittal balance. Both patients who had already undergone surgery at the time of the evaluation and those who were under non-surgical management were included. They had to be able to walk independently without support from crutches, a walker, or a cane. The subjects underwent quantitative kinesiological analysis using a multisensor platform consisting of a depth camera, a surface electromyograph, and a body composition scale.

Degenerative spondylolisthesis was defined as the existence of a forward slippage of a vertebral body in the presence of an intact neural arch, and was diagnosed using simple radiographs of the lumbosacral spine in lateral projection, with the patient in a standing position, in which forward slippage of one vertebra over another of more than 4 millimeters was observed.

We measured the height of the patients in meters. Their body composition was estimated using a TANITA scale, for which they were asked to clean the palms of their hands and the soles of their feet with an alcohol solution, to increase the sensitivity of the scale for the measurements, as recommended by the manufacturer. The following data were obtained: weight; percentage of total fat; percentage of visceral fat; total muscle mass; bone mass; percentage of water.

To perform the quantitative kinesiological analysis of the lumbar spine, Static/Kinematic Analysis and Electrical Activity Analysis were used.

\section{Static/kinematic analysis}

A point cloud map was obtained in order to achieve a threedimensional reconstruction. A depth camera designed for videogame entertainment (Microsoft Kinect) was used to obtain the point clouds. The acquisition system consisted of a base, with its respective camera mounted vertically and positioned at a distance on 186 centimeters from the patient and at a height of 100 centimeters from the floor. (Figure 1) We positioned the patient, preferably dressed in close-fitting, light-colored clothing, in front of the camera. The routine for obtaining the images was explained and they were instructed to perform flexion and extension movements of the lumbar spine. Markers were placed at the auricles and lateral malleoli, as references for the sagittal plane in the images.

The images were obtained using Kinect Fusion Explorer-WPF capture software. A data series (markers) was selected from the three-dimensional reconstruction which, with Matlab (a high-level language with an interactive environment for numerical calculations, visualization, and programming), generated the coefficients of a polynomial of a predetermined grade. Once the image was built,

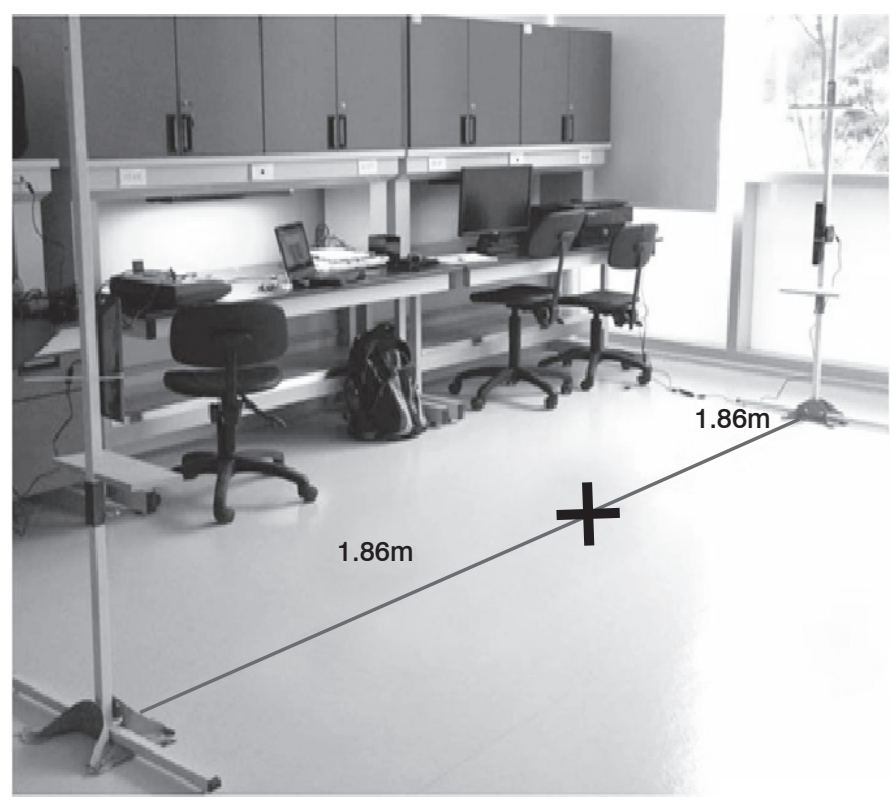

Figure 1. Example of the point cloud image capture towers. There are two towers, each with a depth camera (Kinect) mounted one meter from the floor and 1.86 meters from the " $X$ " that marks the location where the patient is evaluated. 
we dropped a plumb line from the auricle to the support plane. We measured the distance in centimeters in relation to the lateral malleolus. We considered it to be a positive change in sagittal balance when the line was in front of the malleolar marker, a negative change when it fell behind, and neutral balance when it passed over the malleolar marker.

\section{Analysis of electrical activity}

Surface electromyography was used to measure the electrical activity and the level of activation of some of the muscles used in flexion (the anterior rectus abdominis and the abdominal external oblique) and extension (latissimus dorsi and gluteus maximus) of the trunk. The analysis was performed using a BSL PRO System Biopic MP36 to evaluate muscular activity bilaterally. The frequency of the sample was $1000 \mathrm{~Hz}$ and the filters were programmed with a bandwidth of $5-500 \mathrm{~Hz}$.

To take the measurements, we placed electrodes on the patient's skin, along the bilateral paramedian line of the abdomen and low back (sites of anatomical muscle reference), while the reference electrode was placed over the iliac crests. The procedure for obtaining the signals was through movements of extension and flexion of the trunk, with a 5-second interval between positions, as follows:

- Upright position (baseline)

- Flexion of the trunk

- Upright position

- Extension of the trunk

- Upright position

Having obtained the signal, preprocessing was performed directly in the Biopac, then a filter for high responses was applied to the finite impulse of from 80 to $130 \mathrm{~Hz}$, depending on the intensity of the signal in the electromyography. The signals were processed in Matlab with the following elements: (Figures 2 and 3)

- Rectification: conversion of the amplitude of the signal into positive values

- Normalization: extraction of the offset from the signal for reduction of the average value of the baseline

- Smoothing: to obtain the envelope across a moving window of 100 data points

The signal was analyzed in real time to identify the flexionrelaxation phenomena. When there is a sustained flexion, there is myoelectrical silence. The area below the curve of the processed signal was identified using the trapezoidal rule for numeric

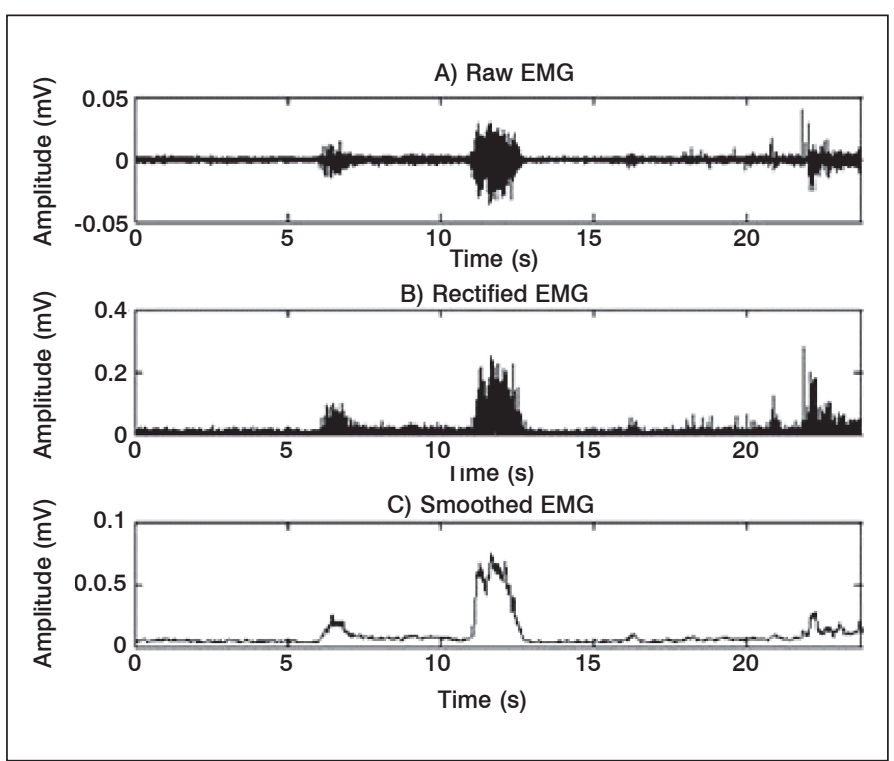

Figure 2. Initial steps in the process of obtaining images from electromyographic noise from muscular activation: A) raw signal, B) rectified signal, and C) smoothed signal. (Example from one patient).

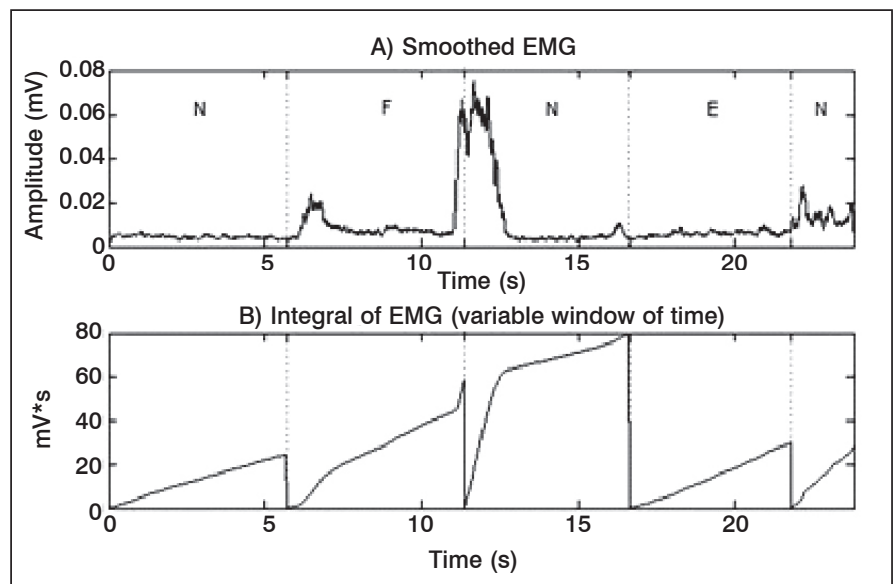

Figure 3. Last steps in the process of obtaining a graphic from electromyographic noise from muscular activation: A) smoothed signal and B) rectified signal.

integration. Subsequently, false colors were applied for the graphic representation, assigning a color according to the percentages of activation, as follows:

- Red (vertical lines): 100-80\%

- Yellow (diagonal lines): $79-60 \%$

- Green (horizontal lines): 59-40\%

- Blue (rectangles): 39-20\%

- Black: $19-0 \%$

Using the data obtained, the change in sagittal balance was analyzed and related to the increase or decrease in muscular activation in neutral and dynamic positions.

\section{RESULTS}

Seven adult patients were included in this study: 5 women (62.5\%) and 2 men (37.5\%), between 18 and 72 years of age (average of 48 years), with diagnoses of pathologies of the lumbar and thoracolumbar spine that could potentially cause changes in sagittal balance, such as spondylolisthesis $(\mathrm{N}=2)$, lumbar fractures $(\mathrm{N}=3)$, stenosis of the lumbar canal $(\mathrm{N}=1)$, and idiopathic scoliosis $(\mathrm{N}=1)$. At the time of evaluation, 4 patients (57.14\%) had already undergone surgery with posterior instrumentation with pedicle screws and posterolateral fusion with autologous graft, and the other 3 patients (42.86\%) were under non-surgical spine management through physical rehabilitation and a healthy lifestyle.

The height of each patient, without shoes, was measured by the same person using a measuring tape. Heights ranged from 1.52 to 1.74 meters (average 1.61 meters). The patients' body weight was between 39.3 and 84 kilograms (average of 68.61 kilograms), with a body mass index (BMI) ranging from 17.31 to 33.32 (average 26.4), distributed as follows: one patient was underweight, two were normal, one was overweight grade I, two were overweight grade II, and one was obese grade I.

According to the images obtained by the depth camera (examples in Figures 4 and 5), sagittal balance ranged from -6.4 to +5.3 centimeters (average of -5.7 centimeters). One patient had neutral sagittal balance, three had positive sagittal balance with an average of $+3.43 \mathrm{~cm}$, and three had negative sagittal balance with an average of $-5.03 \mathrm{~cm}$.

Muscular activation with surface electromyography was integrated, and the percentage of activation of the upper and lower abdominal muscles during flexion was compared with that of the lumbar and gluteus maximus muscles during extension. These were plotted individually for each patient, as shown in the example in Figure 6. Among the patients with positive sagittal balance, the percentage of activation of the abdominal 
muscles was $58.5 \%$, while that of the lumbar muscles was $75.25 \%$. Patients with a negative sagittal balance had a percentage of activation of $70.25 \%$ for the abdominal muscles and $65 \%$ for the lumbar muscles. The patient with neutral sagittal balance had abdominal muscular activation of $87.75 \%$ and lumbar muscular activation of $78.25 \%$.

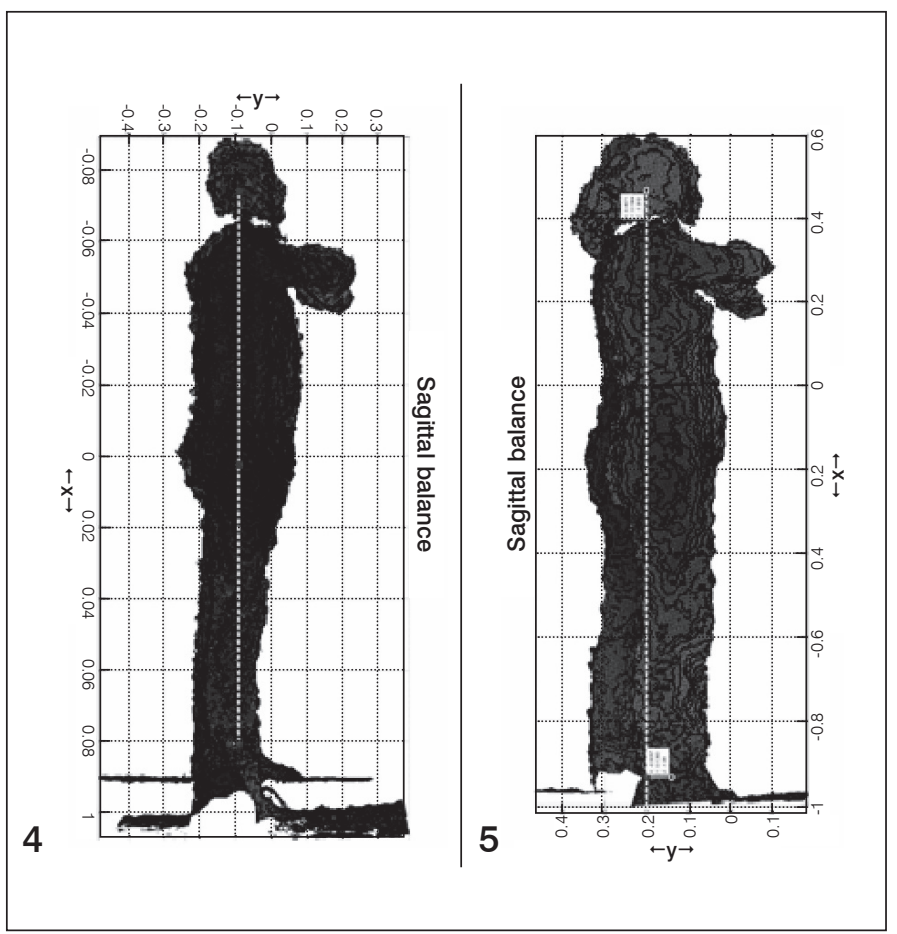

Figures 4 and 5. Three-dimensional point cloud models obtained with the depth camera. The yellow vector marks the plumb line starting at the ear canal opening and ending flush with the floor. The green vector marks the distance between the plumb line and the external malleolus (sagittal balance).

\section{DISCUSSION}

Spinal stability was described by White in 1975 as the capacity of the spine, under physiological loads, to limit displacement patterns so as not to damage or irritate the spinal cord and nerve roots and to prevent incapacitating deformities or pain caused by structural changes. ${ }^{1,2}$ The American Academy of Orthopedic Surgeons defines stability as "the capacity of the vertebrae to stay in alignment and maintain normal displacements for all physiological body movements". ${ }^{17}$

Pope and Panjabi described spinal instability as a loss of rigidity leading to abnormal and increased movement of the mobile segments, ${ }^{1,18,19}$ with a global increase in the normal limits associated with the occurrence of back and/or radicular pain.

One of the most commonly accepted definitions of lumbar spine instability and the loss of segmental rigidity was described by Frymoyer and Shelby, stating that "spine instability and the loss of segmental rigidity is when an abnormal load is applied to the vertebral segment and movements comparable to those of a normal spine are produced". ${ }^{19}$ Other authors define biomechanical instability as a mechanical entity that is not present in normal equilibrium. Depuis (1985) stated that instability is when the movable segments of the lumbar vertebrae show abnormal movements, both in translation and rotation. ${ }^{19}$

The clinical importance and the recognition of compensatory mechanisms are fundamental because they are important elements to take into account when indicating a treatment. Evaluation of sagittal balance must include a parameter to measure the overall equilibrium of the trunk, i.e., the plumb line in $\mathrm{C} 7$ and the sacral plateau, the position of pelvic rotation when bending the pelvis, and a description of the position of the lower limbs. These three parameters were considered by Le Huec et $\mathrm{al}^{8}$ in their assessment method known as full balance integration (FBI). ${ }^{8,20}$ In more severely unbalanced cases, patients present all the signs of postural changes in an attempt to compensate for sagittal imbalance: the trunk leaning forward, retroversion of the pelvis, and apparent flexion, while in reality, there is extension of the hips and flexion of the knees.

In this study, we only evaluated patients with traumatic, degenerative, and idiopathic diseases in which, due to their nature, potential changes to the sagittal balance of the spine are expected.

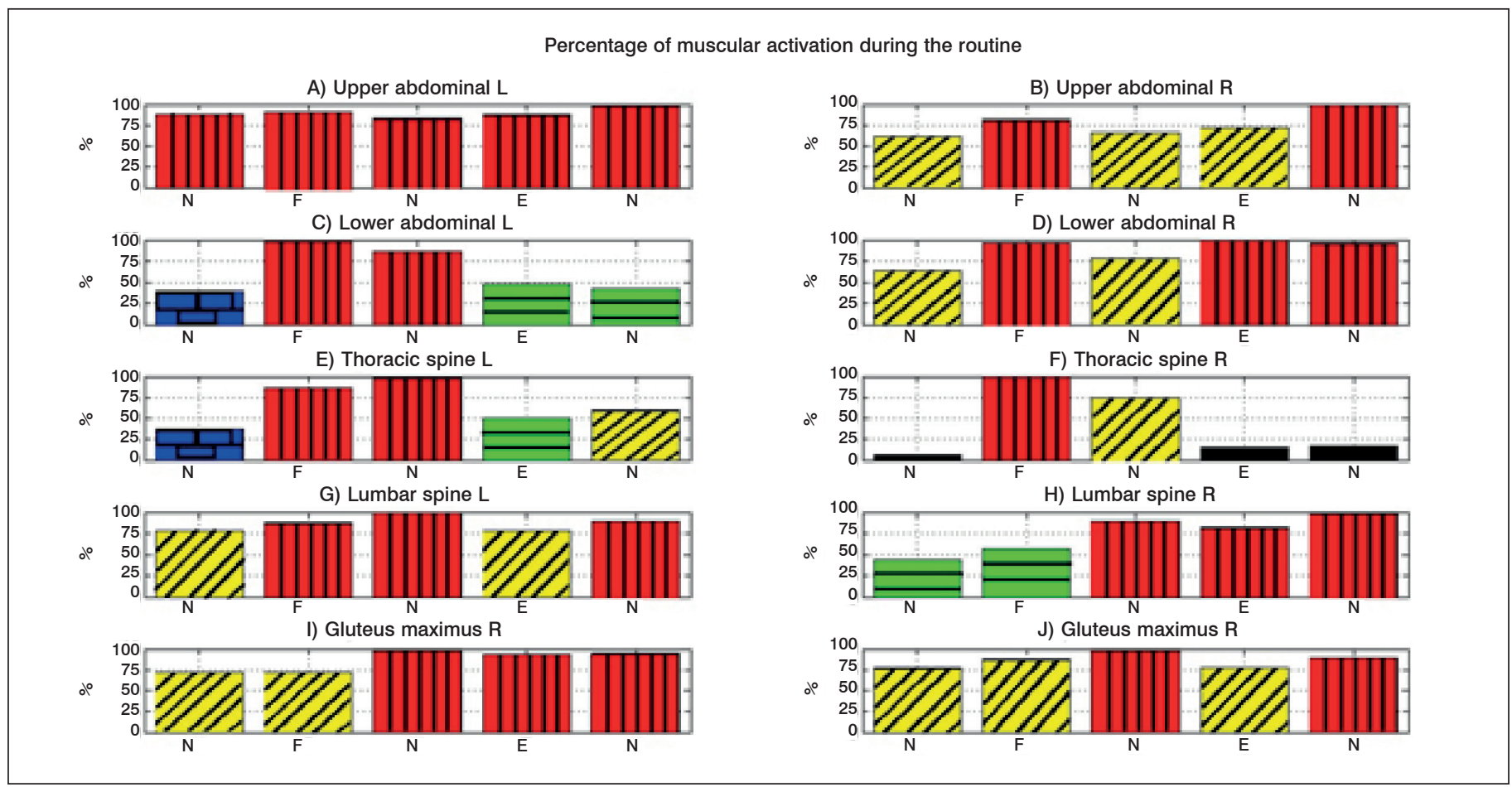

Figure 6. Example of graphs showing the percentage of muscle activation. Red (vertical lines): 100-80\%; Yellow (diagonal lines): 79-60\%; Green (horizontal lines): 59-40\%; Blue (rectangles): 39-20\%; Black: 19-0\%. N= Neutral position; $F=$ Flexion of the trunk; $E=$ Extension of the trunk. (Example of a patient). 
In an attempt to avoid a study in which the patients would be exposed to radiation, we opted to use technologies being developed for evaluation in various medical fields, with depth cameras obtaining schematic images and three-dimensional point cloud reconstruction. Sagittal balance can be measured quantitatively using reference markers at anatomical sites as described by Bernhardt and Bridwell, ${ }^{21}$ who observed that normal sagittal balance is present if a plumb line extends from the external acoustic meatus to the acromion, greater trochanter, lateral condyle of the knee, and the lateral malleolus, while estimating that the sagittal profile is more difficult due to high individual variability. We used the external acoustic meatus and the lateral malleolus of each subject as markers. Three patients had a positive sagittal balance with an average of $3.13 \mathrm{~cm}$, three patients had a negative sagittal balance with an average of $-5.03 \mathrm{~cm}$, and one patients had a neutral sagittal balance. The patients were divided into etiological diagnostic groups: Degenerative, Traumatic, and Idiopathic, and they were identified as pre- and postoperative, as shown in Table 1.

Looking at these figures, we could see that both patients with traumatic conditions (in all cases related to type A lumbar fractures, as classified by the AOSpine) and those who underwent stabilization surgery using posterior instrumentation without release had changes associated with a negative sagittal balance with greater displacement (from -2.7 to -6.4 centimeters). These findings are confirmed by those of Soh et al, ${ }^{22}$ who found that the main disadvantages of surgical fusion in degenerative instability are the loss of mobility and curvature with deterioration of sagittal balance, instrumentation failure, and increased transfer of stress to the adjacent movable segments, referred to as "transition syndrome". They conducted a five-year follow-up with patients who had undergone posterior instrumentation surgery, and showed degenerative changes in adjacent segments due to loss of mobility and changes in mechanical load at the fusion site. The degenerative changes in the adjacent segments included segmental instability, spinal stenosis, intervertebral disc injury, spondylolisthesis, and fractures. ${ }^{22}$

A measurement is needed that is sensitive to the initial degenerative changes, therefore quantitative MRI analysis has been developed to capture early disc degeneration. The method introduced by Sobajima measures the surface area and intensity of the signal of the pulpy nucleus in patients with changes with symptoms of adjacent disc degeneration, and the results provide an index for T2-weighted magnetic resonance images, ${ }^{23}$ from which a correlation can be drawn between the intensity of the signal in magnetic resonance images (MRI) and the composition and condition of the disc. In our study, there was clear evidence of changes in the balance of postoperative patients, which potentially predisposes them to adjacent degenerative changes even before the patient starts to have suspicious symptoms.

Regarding the percentage of muscular activation measured using surface electromyography, in most cases we observed preferential activation in the abdominal musculature, regardless of the deviation of either sagittal balance or average sagittal balance, as shown in Table 2. However, we observed a clear correlation between overweight and obese patients (average BMI of 30, mild obesity) and high activation in the abdominal musculature $(81.5 \%)$. This

Table 1. Relationship between etiology of the disease, previous surgery, and average sagittal balance.

\begin{tabular}{c|c|c|c}
\hline Type of Disease & \multicolumn{2}{|c|}{ Previous surgery } & Average Sagittal Balance \\
\hline \multirow{2}{*}{ Degenerative $(N=3)$} & Yes & 1 & \multirow{2}{*}{$0.66 \mathrm{~cm}$} \\
\cline { 2 - 3 } & No & 2 & \multirow{2}{*}{$-2.9 \mathrm{~cm}$} \\
\hline \multirow{2}{*}{ Traumatic $(\mathrm{N}=3)$} & Yes & 3 & \multirow{2}{*}{$1 \mathrm{~cm}$} \\
\cline { 2 - 4 } & No & 0 & \\
\hline \multirow{2}{*}{ Idiopathic $(\mathrm{N}=1)$} & Yes & 0 & \multirow{2}{*}{} \\
\cline { 2 - 4 } & No & 1 & \\
\hline
\end{tabular}

Table 2. Relationship between sagittal balance, average Body Mass Index (BMI), and the percentage of muscular activation measured using surface electromyography.

\begin{tabular}{c|c|c|c}
\hline Sagittal balance & Average BMI & \multicolumn{2}{|c}{ Percentage of Muscular Activation } \\
\hline \multirow{2}{*}{ Positive } & \multirow{2}{*}{25.24} & Abdominal & $70.25 \%$ \\
\cline { 3 - 4 } & & Lumbar & $65 \%$ \\
\hline \multirow{2}{*}{ Negative } & \multirow{2}{*}{26.67} & Abdominal & $58.50 \%$ \\
\cline { 3 - 4 } & & Lumbar & $75.25 \%$ \\
\hline \multirow{2}{*}{ Neutral } & \multirow{2}{*}{29.07} & Abdominal & $87.75 \%$ \\
\cline { 3 - 4 } & & Lumbar & $78.25 \%$ \\
\hline
\end{tabular}

correlates with that described by Jiménez et al, ${ }^{24}$ who investigate factors that impact fusion in the treatment of lumbar spine stability, such as obesity, alcoholism, smoking, age, sex, and bone density, resulting in the patient's nutritional state affecting the satisfactory outcome, in patients submitted to a stabilization procedure of the lumbar spine, it being important to identify and correct metabolic values early, using supporting measures to achieve optimum fusion results, ${ }^{24}$ since it increases the possibility of developing a thoracic deformity in kyphosis.

Additionally, there was a tendency towards a negative deviation of sagittal balance (50\% vs. $25 \%$ for neutral balance and $25 \%$ for positive balance) in patients who had previously undergone surgery.

The use of depth cameras for point cloud reconstruction is a useful tool for quantitative measurement in conditions that can potentially cause changes to sagittal balance, as it provides a guide for the clinical surgeon that can show the evolution of degenerative diseases and, in situations where posterior instrumentation surgery has been performed, for the evaluation of postoperative results in an attempt to predict the possibilities of disease of the adjacent segment, enabling the proper treatment to be given, in a timely manner. Electromyography shows us the level of muscle activation in these diseases, as part of a compensatory mechanism designed to restore sagittal balance. The body composition scale is a key complement in the clinical evaluation of the patient because, as explained above, nutritional state directly impacts the long-term prognosis in any disease that affects the lumbar spine.

The limitations of this study include the small size of the evaluation sample and the lack of healthy controls for comparison, as well as the fact that we did not mark other anatomical points that could have provided us with data about changes in the total body position, also described as a mechanism to compensate for the lack of sagittal balance. We did not perform traditional radiographical and clinical measurements, which also could have guided us in effectively correlating our results with more thoroughly studied methods.

\section{CONCLUSIONS}

We conclude that the integration of a platform of multiple sensors is a useful, economical, and reliable tool that ensures quantitative, real time measurements to help clinicians in their daily practice in the diagnosis and follow-up of patients with traumatic, degenerative, and idiopathic conditions that lead to a potential sagittal imbalance, as well as with their association with changes in muscular activation caused by the compensatory mechanisms that accompany them. In this study, we identified muscular imbalance and its relationship with the patient's nutritional state and compensatory muscular activation, and we can conclude that the higher the body mass index, the higher the activation of the abdominal musculature, with the consequent predisposition towards kyphotic deformity, and that negative sagittal imbalance in postoperative patients leads to the possibility of developing medium- to long-term disease of the adjacent disc.

New studies must be conducted with higher numbers of patients and healthy controls for comparison, and a user-friendly digital interface for the medical specialist must be built, for the use of the 
suggested platform in evaluations in the consultation surgery and so as to include it as physical material to support effective and timely care for the patient. Work continues on the project, with the manufacture of a wireless electromyograph and the possibility of real time integration of the images obtained with the depth camera with the results of the electromyographical muscular activation percentage.

\section{ACKNOWLEDGEMENTS}

We thank the Instituto Tecnológico de Monterrey Guadalajara campus and its Biotechnology and Health Division, for the human and technological support. We also thank the Centro Médico Nacional de Occidente del Instituto Mexicano del Seguro Social for providing facilities for external consultations. And to everyone who made this study possible.

All authors declare no potential conflict of interest concerning this article.

\section{REFERENCES}

1. Izzo R, Guarnieri G, Guglielmi G, Muto M. Biomechanics of the spine. Part I: spinal stability. Eur J Radiol. 2013:82(1):118-26.

2. White AA 3rd, Johnson RM, Panjabi MM, Southwick WO. Biomechanical analysis of clinical stability in the cervical spine. Clin Orthop Relat Res.1975;(109):85-96.

3. Panjabi MM. Clinical spinal instability and low back pain. J Electromyogr Kinesiol. 2003;13(4):371-9.

4. White AA 3rd, Panjabi MM. The basic kinematics of the human spine. A review of past and current knowledge. Spine (Phila Pa 1976). 1978:3(1):12-20.

5. Barrey C, Jund J, Noseda O, Roussouly P. Sagittal balance of the pelvis-spine complex and lumbar degenerative diseases. A comparative study about 85 cases. Eur Spine J. 2007:16(9):1459-67.

6. Barrey C, Jund J, Perrin G, Roussouly P. Spinopelvic alignment of patients with degenerative spondylolisthesis. Neurosurgery. 2007;61(5):981-6.

7. Berthonnaud $E$, Dimnet J, Roussouly $P$, Labelle $H$. Analysis of the sagittal balance of the spine and pelvis using shape and orientation parameters. J Spinal Disord Tech. 2005;18(1):40-7.

8. Le Huec JC, Charosky S, Barrey C, Rigal J, Aunoble S. Sagittal imbalance cascade for simple degenerative spine and consequences: algorithm of decision for appropriate treatment. Eur Spine J. 2011;20(Suppl 5):699-703.

9. Colloca CJ, Hinrichs RN. The biomechanical and clinical significance of the lumbar erector spinae flexion-relaxation phenomenon: a review of literature. J Manipulative Physiol Ther. 2005;28(8):623-31.

10. O'Sullivan PB. Lumbar segmental 'instability': clinical presentation and specific stabilizing exercise management. Man Ther. 2000;5(1):2-12.

11. Clark RA, Pua YH, Fortin K, Ritchie C, Webster KE, Denehy L, Bryant AL. Validity of the Microsoft Kinect for assessment of postural control. Gait Posture. 2012;36(3):372-7.

12. Yang MT, Chuang MW. Fall risk assessment and early-warning for toddler behaviors at home. Sensors (Basel). 2013:13(12):16985-7005

13. Kurillo G, Chen A, Bajcsy R, Han JJ. Evaluation of upper extremity reachable workspace using Kinect camera. Technol Health Care. 2013;21(6):641-56.

14. González-Ortega D, Díaz-Pernas FJ, Martínez-Zarzuela M, Antón-Rodríguez M. A Kinect-based system for cognitive rehabilitation exercises monitoring. Comput Methods Programs Biomed. 2014;113(2):620-31.

15. Vernadakis N, Derri V, Tsitskari E, Antoniou P. The effect of Xbox Kinect intervention on balance ability for previously injured young competitive male athletes: a preliminary study. Phys Ther Sport. 2014;15(3):148-55.

16. Holmes H, Wood J, Jenkins S, Winship P, Lunt D, Bostock S, Hill K. Xbox Kinect ${ }^{\mathrm{TM}}$ represents high intensity exercise for adults with cystic fibrosis. J Cyst Fibros. 2013;12(6):604-8.

17. Kirkaldy-Willis WH. Presidential symposium on instability of the lumbar spine. Introduction. Spine. 1985;10:254.

18. Medeiros da Costa L, Hennemann SF, Rodrigues de Abreu M, Lacombe Antoneli PH. Correlação entre instabilidade radiográfica e presença do sinal de modic. Coluna/Columna. 2011;10(2):132-5.

19. Mulholland RC. The myth of lumbar instability: the importance of abnormal loading as a cause of low back pain. Eur Spine J. 2008;17(5):619-25.

20. Lamartina C, Berjano P, Petruzzi M, Sinigaglia A, Casero G, Cecchinato R, et al. Criteria to restore the sagittal balance in deformity and degenerative spondylolisthesis. Eur Spine J. 2012;21(Suppl 1):27-31.

21. Bernhardt M, Bridwell $\mathrm{KH}$. Segmental analysis of the sagittal plane alignment of the normal thoracic and lumbar spines and thoracolumbar junction. Spine (Phila Pa 1976). 1989:14(7):717-21.

22. Soh J, Lee JC, Shin BJ. Analysis of risk factors for adjacent segment degeneration occurring more than 5 years after fusion with pedicle screw fixation for degenerative lumbar spine. Asian Spine J. 2013;7(4):273-81.

23. Fan SW, Zhou ZJ, Hu ZJ, Fang XQ, Zhao FD, Zhang J. Quantitative MRI analysis of the surface area, signal intensity and MRI index of the central bright area for the evaluation of early adjacent disc degeneration after lumbar fusion. Eur Spine J. 2012;21(9):1709-15.

24. Jiménez Ávila JM, García Valencia J, Bitar Alatorre WE. Factores de riesgo que afectan la fusión en el tratamiento de la inestabilidad en la columna lumbar. Coluna/Columna. 2010;9(3):304-8. 